\section{Use of Statins for Secondary Prevention and Primary Prevention of Ischemic Stroke}

\section{Wilbert S. Aronow*}

Department of Medicine, Division of Cardiology, New York Medical College, Westchester Medical Center, New York, USA

\begin{abstract}
Numerous randomized, double-blind, placebo-controlled studies and observational studies have shown that statins reduce ischemic stroke in high-risk persons with hypercholesterolemia. The 2013 American College of Cardiology (ACC)/American Heart Association guidelines on treatment of hypercholesterolemia supports the use of statins in 4 major groups. Patients with clinical atherosclerotic cardiovascular disease including those with stroke or transient ischemic attack should be treated with high-dose statins. High-dose statins reduce serum LDL cholesterol $\geq 50 \%$ and include atorvastatin 40 to $80 \mathrm{mg}$ daily and rosuvastatin 20 to $40 \mathrm{mg}$ daily. Patients with a serum LDL cholesterol $\geq 190 \mathrm{mg} / \mathrm{dl}$ should also be treated with high-dose statins. The ACC/AHA guidelines recommend for primary prevention in diabetics with a serum LDL cholesterol between 70 to $189 \mathrm{mg} / \mathrm{dl}$ moderate-dose statins. If the 10-year risk of developing atherosclerotic cardiovascular disease (coronary heart disease, stroke, transient ischemic attack, or atherosclerotic peripheral arterial disease) by the Pooled Cohort Equations is $\geq 7.5 \%$, high-dose statins should be administered. Persons aged 40 to 75 years without atherosclerotic cardiovascular disease or diabetes mellitus with a serum LDL cholesterol between 70 to 189 $\mathrm{mg} / \mathrm{dl}$ and an estimated 10-year risk of developing atherosclerotic vascular disease of $\geq 7.5 \%$ should be treated with high-dose statins. It is reasonable to treat persons aged 40 to 75 years without atherosclerotic vascular disease or diabetes mellitus with serum LDL cholesterol between 70 to $189 \mathrm{mg} / \mathrm{dl}$ and an estimated 10-year risk of developing atherosclerotic cardiovascular disease of $5 \%$ to $7.4 \%$ with moderate-dose statins.
\end{abstract}

Keywords: Lipids; Statins; Lipid-lowering drugs; Atherosclerotic cardiovascular disease; Stroke; Transient ischemic attack; Serum low-density lipoprotein cholesterol

${ }^{\star}$ Corresponding author: Wilbert S. Aronow, MD, FACC, FAHA, Department of Medicine, Cardiology Division, New York Medical College, Westchester Medical Center, Macy Pavilion, Room 138, Valhalla, NY 10595, USA, Tel: 914-493-5311; Fax: 914-235-6274; E-mail: WSAronow@aol.com

Citation: Aronow WS (2014) Use of Statins for Secondary Prevention and Primary Prevention of Ischemic Stroke. J Cardiol Stud Res 1: 001.

Received: May 08, 2014; Accepted: June 20, 2014; Published: July 04, 2014

Copyright: (C) 2014 Aronow WS. This is an open-access article distributed under the terms of the Creative Commons Attribution License, which permits unrestricted use, distribution, and reproduction in any medium, provided the original author and source are credited.

\section{Introduction}

Hypercholesterolemia was a risk factor for stroke in 1,834 elderly persons [1]. There was a 1.06 times higher probability of developing an Atherothrom Botic Infarction (ABI) for an increment of $10 \mathrm{mg} / \mathrm{dl}$ of serum total cholesterol after controlling for other prognostic variables. A low serum High-Density Lipoprotein (HDL) cholesterol is also a risk factor for stroke [1,2]. There was a 1.27 times higher probability of developing an Atherothrom Botic Infarction (ABI) for a decrement of $10 \mathrm{mg} / \mathrm{dl}$ of serum HDL cholesterol after controlling for other prognostic variables. Statins are the only lipid-lowering drugs that have been shown to reduce the incidence of ischemic stroke in patients at risk for ischemic stroke. This review article will discuss the studies demonstrating the efficacy of statins in preventing ischemic stroke and the current guidelines supporting this use of statins. The search strategy for this review article included a review of all articles on this topic published in PubMed. The search terms used were stroke, transient ischemic attack, atherothrombotic brain infarction, statins, lipid-lowering drugs, hypercholesterolemia, dyslipidemia, serum lipids, serum low-density lipoprotein cholesterol atherosclerotic cardiovascular disease, hypertension, and diabetes mellitus.

\section{Randomized, Double-Blind Clinical Trials}

At 5.4-year median follow-up of 4,444 men and women (of whom 1,021 were 65 to 70 years of age at study entry) with Coronary Heart Disease (CHD) and hypercholesterolemia in the Scandinavian Simvastatin Survival Study, compared with double-blind placebo, simvastatin $20 \mathrm{mg}$ to $40 \mathrm{mg}$ daily significantly reduced cerebrovascular events by $30 \%$ [Table 1] $[3,4]$. The reduction in stroke was similar in older and in younger men and women. At 5-year median follow-up of 1,283 patients aged 65 to 74 years at study entry in the Cholesterol and Recurrent Events study involving pravastatin treatment for a period of 5 years in post-myocardial infarction patients and serum total cholesterol levels less than $240 \mathrm{mg} / \mathrm{dl}$ and serum Low-Density Lipoprotein (LDL) cholesterol levels of 115 to 174 $\mathrm{mg} / \mathrm{dl}$, compared with double-blind placebo, pravastatin $40 \mathrm{mg}$ daily significantly decreased stroke by $40 \%$ [Table 1] [5].

The Heart Protection Study randomized 20,536 men and women $(5,806$ of whom were aged 70 to 80 years) with prior myocardial infarction (8,510 persons), other CHD (4,876 persons), and no CHD $(7,150$ persons) and a serum total cholesterol level of $135 \mathrm{mg} / \mathrm{dl}$ or higher to simvastatin $40 \mathrm{mg}$ daily or to double-blind placebo [6] of the 7,150 persons without $\mathrm{CHD}, 25 \%$ had cerebrovascular disease. At 5-year follow-up, compared to placebo, simvastatin significantly decreased any stroke by $25 \%$ [Table 1] [6]. The significant reduction in stroke occurred regardless of initial levels of serum lipids, age, or gender. In the Myocardial Ischemia Reduction with Aggressive Cholesterol Lowering study, 3,086 persons, mean age 65 years, with an acute coronary syndrome and a mean serum LDL cholesterol level of $124 \mathrm{mg} / \mathrm{dl}$ were randomized to atorvastatin $80 \mathrm{mg}$ daily or to double-blind placebo 24 to 96 hours after hospitalization for 16 weeks [7]. At 16-week follow-up, compared with placebo, atorvastatin significantly decreased stroke by $50 \%$ [Table 1] [7]. 


\begin{tabular}{|c|c|c|c|c|}
\hline \multicolumn{5}{|c|}{ Double-Blind, Placebo-Controlled, Randomized Clinical Trials } \\
\hline Number & Follow-up & Statin & Reduction in Stroke (\%) & Reference \\
\hline 4,444 & 5.4 years & simvastatin & 30 & {$[3,4]$} \\
\hline 1,283 & 5.0 & pravastatin & 40 & {$[5]$} \\
\hline 20,536 & 5.0 years & simvastatin & 25 & {$[6]$} \\
\hline 3,086 & 16 weeks & atorvastatin & 50 & {$[7]$} \\
\hline 10,305 & 3.3 years & atorvastatin & 27 & {$[8]$} \\
\hline 2,838 & 3.9 years & atorvastatin & 48 & {$[9]$} \\
\hline 4,731 & 4.9 years & atorvastatin & 16 & {$[10]$} \\
\hline $17,082^{*}$ & 1.9 years & rosuvastatin & 48 & {$[11]$} \\
\hline \multicolumn{5}{|c|}{ Observational Studies With Different Statins Prescribed By Physicians } \\
\hline 1,410 & 3.0 years & & 60 & {$[16]$} \\
\hline 529 & 29 months & 47 & {$[17]$} \\
\hline 449 & 26 months & 87 & {$[18]$} \\
\hline
\end{tabular}

Table 1: Use of Statins for Secondary Prevention and Primary Prevention of Ischemic Stroke.

* primary prevention trial

In the Lipid Lowering Arm of the Anglo-Scandinavian Cardiac Outcomes trial, 10,305 persons (6,570 aged 61 to 79 years) with hypertension and at least 3 other cardiovascular risk factors with no history of CHD and a mean serum LDL cholesterol of $133 \mathrm{mg} / \mathrm{dl}$ were randomized to atorvastatin $10 \mathrm{mg}$ daily or to double-blind placebo [8]. At 3.3-year follow-up, compared with placebo, atorvastatin significantly decreased fatal and nonfatal stroke by 27\% [Table 1] [8]. In the Collaborative Atorvastatin Diabetes Study, 2,838 patients ( $62 \%$ older than 60 years) with diabetes mellitus, no cardiovascular disease, and a serum LDL cholesterol less than $160 \mathrm{mg} / \mathrm{dl}$ were randomized to atorvastatin $10 \mathrm{mg}$ daily or to double-blind placebo [9]. At 3.9-year median follow-up, compared with placebo, atorvastatin significantly reduced stroke by $48 \%$ [Table 1] [9].

In the Stroke Prevention by Aggressive Reduction in Cholesterol Levels study, 4,731 patients, mean age 63 years, who had a stroke or transient ischemic attack within 1 to 6 months prior to study entry, a serum LDL cholesterol of 100 to $190 \mathrm{mg} / \mathrm{dl}$, and no CHD were randomized to atorvastatin $80 \mathrm{mg}$ daily or to double-blind placebo [10]. At 4.9-year median follow-up, atorvastatin significantly reduced the incidence of new stroke by $16 \%$ [Table 1] [10]. In the Justification for the Use of Statins in Prevention : an Intervention Trial evaluating Rosuvastatin, 17,082 apparently healthy persons, median age 66 years, with a serum LDL cholesterol of less than $130 \mathrm{mg} / \mathrm{dl}$ and high-sensitivity C-reactive protein levels of $2.0 \mathrm{mg} / \mathrm{L}$ or higher were randomized to rosuvastatin $20 \mathrm{mg}$ daily or to doble-blind placebo [11]. At 1.9-year median follow-up, rosuvastatin significantly reduced the incidence of any stroke by $48 \%$ [Table 1] [11].

A meta-analysis was performed in 9 randomized trials of statins for secondary prevention in 19, 569 patients aged 65 to 82 years [12]. Over 5 years, statins significantly reduced the incidence of stroke by $25 \%$ [12]. A meta-analysis performed in 26 randomized trials of 170,000 patients showed that compared with less intensive statin therapy, intensive statin therapy significantly reduced ischemic stroke further by $16 \%$ [13]. A meta-analysis was performed in 14 randomized trials of statins in 18,686 diabetics, mean age 63 years, (1,466 with type 1 diabetes and 17, 220 with type 2 diabetes) [14]. After 4.3-year mean follow-up, statins significantly reduced the incidence of stroke by $21 \%$ [14].
Randomized placebo-controlled trials have not demonstrated a significant reduction in stroke by other lipid-lowering drugs. Among 3,414 patients, mean age 64 years, with atherosclerotic cardiovascular disease and low serum HDL cholesterol levels treated with simvastatin plus ezetimibe if needed to maintain the serum LDL cholesterol less than $70 \mathrm{mg} / \mathrm{dl}$, at 36 -month follow-up, patients randomized to niacin had improvements in serum HDL cholesterol and triglyceride levels but no clinical improvement compared to patients randomized to placebo [15]. In this study, patients treated with niacin had a $67 \%$ increase in ischemic stroke or stroke of uncertain origin $(P=0.09)$ [15].

\section{Observational Studies}

In all of the observational prospective studies performed by this author, the attitude of the different physicians toward treating hypercholesterolemia in high-risk older persons determined whether or not statins were prescribed. In an observational prospective study of 488 men and 922 women, mean age 81 years, with prior myocardial infarction and a serum LDL cholesterol of $125 \mathrm{mg} / \mathrm{dl}$ or higher, $48 \%$ of persons were treated with statins [16]. At 3-year follow-up, compared to no treatment with statins, use of statins significantly decreased the incidence of stroke by $60 \%$ [Table 1] [16], Statins significantly decreased new stroke in persons aged 90 years and younger but not in persons older than 90 years [16]. Decreasing serum LDL cholesterol to less than $90 \mathrm{mg} / \mathrm{dl}$ was associated with a $7 \%$ incidence of new stroke, whereas decreasing serum LDL cholesterol to 90 to $99 \mathrm{mg} / \mathrm{dl}$ was associated with a $16 \%$ incidence of new stroke [16]. The lower the serum LDL cholesterol in elderly persons treated with statins, the greater was the decrease in new stroke [16].

In an observational prospective study of 171 men and 358 women, mean age 79 years, with prior myocardial infarction, diabetes mellitus, and a serum LDL cholesterol of $125 \mathrm{mg} / \mathrm{dl}$ or higher, $53 \%$ of persons were treated with statins [17]. At 29-month follow-up, compared with no treatment with statins, use of statins significantly decreased in elderly diabetics with prior myocardial infarction the incidence of stroke by $47 \%$ [Table 1] [17]. Of 449 patients, mean age 72 years, with severe carotid arterial disease who did not undergo revascularization, 298 (66\%) were treated with statins [18]. Follow-up was 26 months in patients treated with statins and 21 months in patients not treated with statins. Stepwise Cox regression analysis showed that use of statins reduced the time to development of new stroke or new myocardial infarction or death by $87 \%(\mathrm{p}<0.0001)$ [Table 1] [18]. Randomized clinical trials need to be performed to confirm the validity of these data [18].

\section{Treatment Guidelines}

Lifestyle measures are important in the treatment of dyslipidemia. The person should achieve and maintain a desirable weight. The diet should be low in cholesterol (less than $200 \mathrm{mg}$ daily). Less than $30 \%$ of total caloric intake should be fatty acids. Saturated fatty acids should comprise less than $7 \%$ of total calories, polyunsaturated acids up to $10 \%$ of total calories, and monounsaturated fatty acids $10 \%$ to $15 \%$ of total calories. The diet should also be high in fiber and high in fruits and vegetables. There is no strong evidence to support any dietary supplements. A more liberalized diet is warranted in elderly persons prone to malnutrition. Moderate intensity exercise is recommended for 30 to 60 minutes daily. Smoking should be stopped, hypertension treated, and diabetes controlled. Secondary causes of dyslipidemia should be treated. 
The 2013 American College of Cardiology (ACC)/American Heart Association guidelines on treatment of hypercholesterolemia support the use of statins in 4 major groups [19]. Patients with clinical atherosclerotic cardiovascular disease including those with stroke or transient ischemic attack should be treated with high-dose statins. High-dose statins reduce serum LDL cholesterol $\geq 50 \%$ and include atorvastatin 40 to $80 \mathrm{mg}$ daily and rosuvastatin 20 to $40 \mathrm{mg}$ daily. Patients with a serum LDL cholesterol $\geq 190 \mathrm{mg} / \mathrm{dl}$ should also be treated with high-dose statins. The ACC/AHA guidelines recommend for primary prevention in diabetics with a serum LDL cholesterol between 70 to $189 \mathrm{mg} / \mathrm{dl}$ moderate-dose statins. If the 10 -year risk of developing atherosclerotic cardiovascular disease (coronary heart disease, stroke, transient ischemic attack, or atherosclerotic peripheral arterial disease) by the Pooled Cohort Equations is $\geq 7.5 \%$, high-dose statins should be administered. Persons aged 40 to 75 years without atherosclerotic cardiovascular disease or diabetes mellitus with a serum LDL cholesterol between 70 to $189 \mathrm{mg} / \mathrm{dl}$ and an estimated 10-year risk of developing atherosclerotic cardiovascular disease of $\geq 7.5 \%$ should be treated with high-dose statins. It is reasonable to treat persons aged 40 to 75 years without atherosclerotic cardiovascular disease or diabetes mellitus with a serum LDL cholesterol between 70 to $189 \mathrm{mg} / \mathrm{dl}$ and an estimated 10-year risk of developing atherosclerotic cardiovascular disease of $5 \%$ to $7.4 \%$ with moderate-dose statins [19].

\section{References}

1. Aronow WS, Ahn C (1994) Correlation of serum lipids with the presence or absence of atherothrombotic brain infarction and peripheral arterial disease in 1,834 men and women aged $\geq 62$ years. Am J Cardiol 73: 995-997.

2. Bihari-Varga M, Szekely J, Gruber E (1981) Plasma high density lipoproteins in coronary, cerebral and peripheral vascular disease: The influence of various risk factors. Atherosclerosis 40: 337-345.

3. Scandinavian Simvastatin Survival Study Group (1994) Randomised trial of cholesterol lowering in 4444 patients with coronary heart disease: The Scandinavian Simvastatin Survival Study (4S). Lancet 344: 1383-1389.

4. Miettinen TA, Pyörälä K, Olsson AG, Musliner TA, Cook TJ, et al. (1997) Cholesterol-lowering therapy in women and elderly patients with myocardial infarction or angina pectoris. Findings from the Scandinavian Simvastatin Survival Study (4S). Circulation 96: 4211-4218.

5. Lewis SJ, Moye LA, Sacks FM, Johnstone DE, Timmis G, et al. (1998) Effect of pravastatin on cardiovascular events in older patients with myocardial infarction and cholesterol levels in the average range: Results of the Cholesterol and Recurrent Events (CARE) Trial. Ann Intern Med 129: 681-689.

6. Heart Protection Study Collaborative Group (2002) MRC/BHF Heart Protection Study of cholesterol lowering with simvastatin in 20,536 high-risk individuals: a randomised placebo-controlled trial. Lancet 360: 7-22.

7. Schwartz GG, Olsson AG, Ezekowitz MD, Ganz P, Oliver MF, et al. (2001) Effects of atorvastatin on early recurrent ischemic events in acute coronary syndromes. The MIRACL study: a randomized controlled trial. JAMA 285 1711-1718.
8. Sever PS, Dahlof B, Poulter NR, Wedel H, Beevers G, et al. (2003) Prevention of coronary and stroke events with atorvastatin in hypertensive patients who have average or lower-than-average cholesterol concentrations, in the Anglo-Scandinavian Cardiac Outcomes Trial-Lipid Lowering Arm (ASCOT-LLA): a multicentre randomised controlled trial. Lancet 361: 1149-1158.

9. Colhoun HM, Betteridge D J, Durrington PN, Hitman GA, Neil HAW, et al. (2004) Primary prevention of cardiovascular disease with atorvastatin in type 2 diabetes in the Collaborative Atorvastatin Diabetes Study (CARDS): multicentre randomized placebo-controlled trial. Lancet 364: 685-696.

10. (2006) The Stroke Prevention by Aggressive Reduction in Cholesterol Levels (SPARCL) Investigators. High-dose atorvastatin after stroke or transient ischemic attack. N Engl J Med 355: 549-559.

11. Ridker PM, Danielson E, Fonseca FA, Genest J, Gotto AM, et al. (2008) Rosuvastatin to prevent vascular events in men and women with elevated C-reactive protein. N Engl J Med 359: 2195-2207.

12. Afilalo J, Duque G, Steele R, Jukema JW, Craen AJM, et al. (2008) Statins for secondary prevention in elderly patients: a hierarchical bayesian meta-analysis. J Am Coll Cardiol 51: 37-45.

13. Cholesterol Treatment Trialists' (CTT) Collaboration, Baigent C, Blackwell L, Emberson J, Holland LE, et al. (2010) Efficacy and safety of more intensive lowering of LDL cholesterol: a meta-analysis of data from 170,000 participants in 26 randomised trials. Lancet 376: 1670-1681.

14. Cholesterol Treatment Trialists' (CTT) Collaborators, Kearney PM, Blackwell L, Collins R, Keech A, et al. (2008) Efficacy of cholesterol-lowering therapy in 18686 people with diabetes in 14 randomised trials of statins: a meta-analysis. Lancet $371:$ 117-125.

15. Boden WE, Probstfield JL, Anderson T, Chaitman BR, Nickens PD, et al. (2011) Niacin in patients with low HDL cholesterol levels receiving intensive statin therapy. N Engl J Med 365: 2255-2267.

16. Aronow WS, Ahn C, Gutstein H (2002) Incidence of new atherothrombotic brain infarction in older persons with prior myocardial infarction and serum low-density lipoprotein cholesterol $\geq 125 \mathrm{mg} / \mathrm{dL}$ treated with statins versus no lipid-lowering drug. J Gerontol: Med Sci 57A: M333-M335.

17. Aronow WS, Ahn C, Gutstein H (2002) Reduction of new coronary events and new atherothrombotic brain infarction in older persons with diabetes mellitus, prior myocardial infarction, and serum low-density lipoprotein cholesterol $\geq 125 \mathrm{mg} / \mathrm{dL}$ treated with statins. J Gerontol: Med Sci 57A: M747-M750.

18. Ravipati G, Aronow WS, Ahn C, Channamsetty V, Sekhri V (2006) Incidence of new stroke or new myocardial infarction or death in patients with severe carotid arterial disease treated with and without statins. Am J Cardiol 98: 1170-1171.

19. Stone NJ, Robinson J, Lichtenstein AH, Merz CNB, Blum CB, et al. (2013) ACC/AHA guideline on the treatment of blood cholesterol to reduce atherosclerotic cardiovascular risk in adults: a report of the American College of Cardiology/American Heart Association Task Force on Practice Guidelines. Circulation. 